\title{
Left Posterolateral Segment
}

National Cancer Institute

\section{Source}

National Cancer Institute. Left Posterolateral Segment. NCI Thesaurus. Code C79732.

Couinaud segment II, corresponding to the lateral segment of the left lobe of the liver, located to the left of the superior portion of the falciform ligament and the fissure for the ligamentum venosum. 